\title{
Seasonal changes in distribution and habitat differences among dolphins in the eastern tropical Pacific
}

\author{
Stephen B. Reilly \\ Southwest Fisheries Center, National Marine Fisheries Service, National Oceanic and Atmospheric Administration, \\ PO Box 271, La Jolla, California 92038, USA
}

\begin{abstract}
Large-scale patterns of dolphin distribution and oceanography were studied from research-vessel surveys conducted in the pelagic eastern tropical Pacific during June to November 1982, 1986 and 1987. Substantial changes were observed in relation to previously reported winter distributions for spotted and/or spinner dolphin schools (Stenella attenuata and/or S. longirostris)and for striped dolphin schools ( $S$. coeruleoalba). These dolphin species were sighted in abundance west of $120^{\circ} \mathrm{W}$ along $10^{\circ} \mathrm{N}$ coincident with seasonal shoaling of a thermocline ridge. No seasonal distribution changes were observed for common dolphin schools (Delphinus delphis); as in the winter, they occupied upwelling-modified waters of the region. Highest-density areas for the 3 school types were clearly separated spatially, and the thermocline depths and sigma-t's of sighting localities were statistically different between spotted/spinner dolphin schools and common dolphin schools. Striped dolphin schools could not be discriminated from the other 2 types based on these habitat variables, indicating other factors or processes contribute to the observed spatial separation of the 3 distributions.
\end{abstract}

\section{INTRODUCTION}

Unlike large whales, the smaller cetaceans are not known to undertake extensive seasonal migrations (Gaskin 1982). Among the delphinids, smaller-scale seasonal movements have been observed for some temperate, relatively coastal populations, apparently in response to seasonal movements of prey (Jonsgard \& Lyshoel 1970, Mercer 1975, Condy et al. 1978, Leatherwood \& Walker 1979, Selzer \& Payne 1988) or seasonal habitat fluctuations (Tomilin 1967. Miyazaki et al. 1974, Viale 1985)

Seasonal distribution changes have not been clearly documented for dolphin populations in the tropics, where seasonal environmental changes are relatively small (Pickard \& Emery 1982). Returns from 7 tagged spotted dolphins Stenella attenuata in the eastern tropical Pacific (ETP) suggest an E-W movement pattern, but these data are too few to be conclusive (Perrin et al. 1979). One objective of this study was to test for seasonal shifts in distributions of eastern tropical Pacific dolphins, and if observed, to examine possible relationships with seasonal environmental changes. A second, related objective was to quantify the associations of dolphin distributions with simple indices of physical habitat, and test for habitat differences among species.

Aggregations of pelagic dolphins, tunas and birds regularly forage together in the eastern tropical Pacific (Perrin 1969, Au \& Perryman 1985), Four dolphin species are involved: spotted dolphins, spinner dolphins Stenella longirostris, striped dolphins $S$. coeruleoalba and common dolphins Delphinus delphis. However, most aggregations contain spotted and spinner dolphins, or just spotted dolphins. Common dolphins are infrequently found with both birds and tunas, and striped dolphins are only rarely involved. Dolphins are incidentally killed in the course of commercial purse seine tuna fishing in the ETP, raising concerns for their conservation (Smith 1983, Perrin 1988).

Historical distribution ranges of spotted, spinner, striped and common dolphins in the ETP (Figs. 1 and 2) have been defined from summaries of many thousands of sighting and collection localities (Evans 1975, Perrin 1975, Perrin et al. 1983, 1985). Au \& Perryman (1985) investigated distribution patterns and habitat relationships within these ranges during the northern winter (January to March), from research-vessel sighting surveys. They reported 2 complementary patterns. In 
winter, spotted and spinner dolphins (Fig. 1) occurred primarily north of the equator extending offshore from the coast of Mexico and Central America, but also south of the Galapagos Islands. Common and striped dolphins occurred primarily along the equator, off Baja California, Costa Rica, and northern South America (Fig. 2). Au \& Perryman (1985) hypothesized from these patterns that spotted and spinner habitat was characterized by warm, low-saline tropical waters where intermediate to shallow thermoclines and relatively small annual variations in surface conditions occurred. In contrast, they hypothesized common and striped dolphin habitat to be characterized by cooler, more saline 'upwelling-modified' waters. Major concentrations of dolphins along $10^{\circ} \mathrm{N}$, between 120 and $150^{\circ} \mathrm{W}$, were noticeably absent in the winter data (Figs. 1 and 2). These western concentrations are a dominant feature of the known historical distributions, suggesting that they are a seasonal feature, not present in the winter.
In this study geographic patterns of dolphin sightings made from research vessels during the northern summer were examined in comparison with winter sighting patterns reported by $\mathrm{Au} \&$ Perryman (1985) for evidence of seasonal distribution changes. Their hypotheses were also tested about habitat characteristics and separation among dolphin school types.

\section{STUDY AREA}

Basic oceanographic patterns. The basic physical features of the upper ocean in the eastern tropical Pacific have been described by Wooster \& Cromwell (1958), Wyrtki (1964, 1965a, b, 1966, 1967), and Tsuchiya $(1970,1974,1982)$. The major surface water masses and currents are shown in Fig. 3.

A permanent, shallow thermocline underlies most of the region, shoaling to the east, with summer thermo-
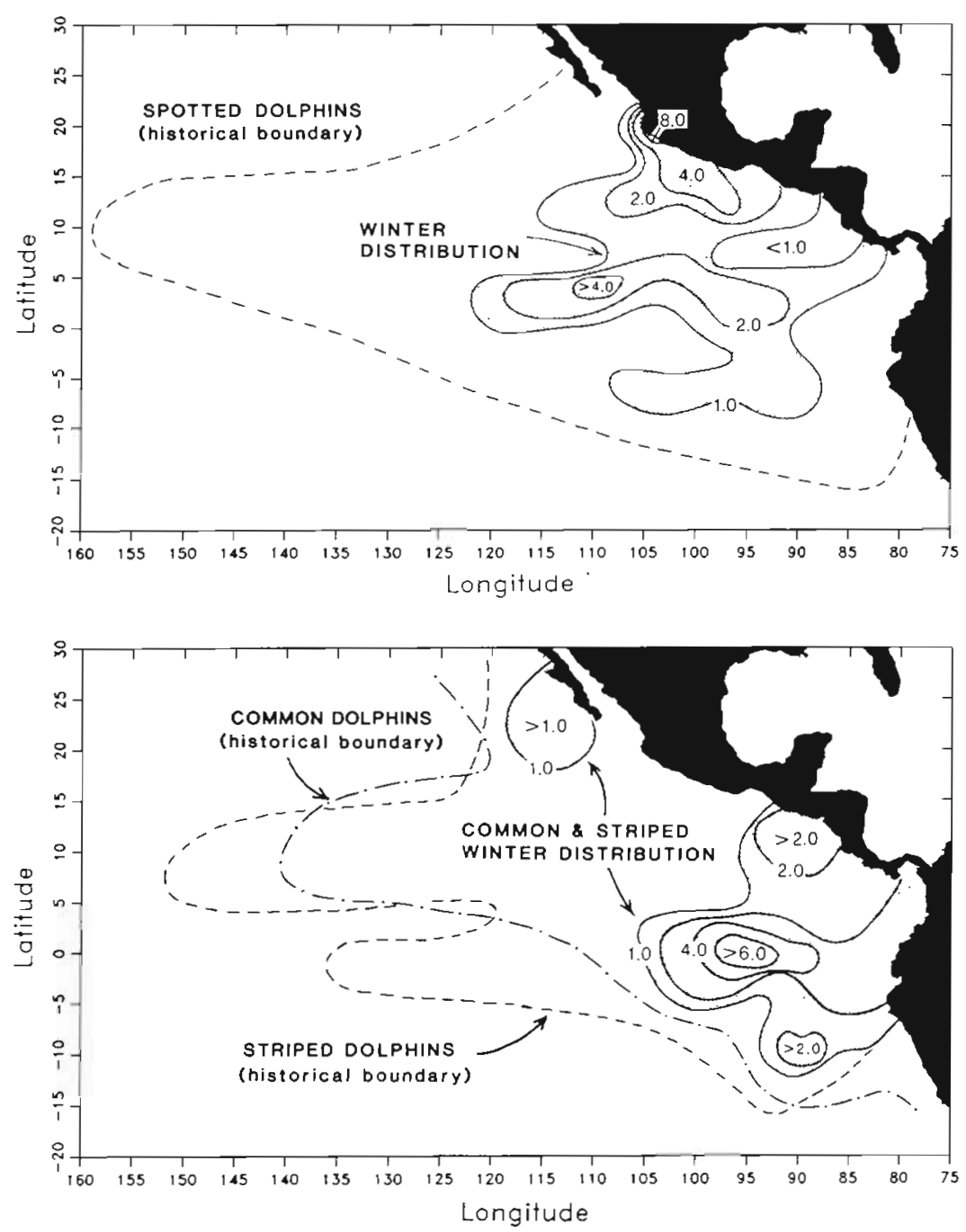

Fig. 1. Stenella attenuata and S. longirostris Spotted and spinner dolphin historical distribution boundary (shown dashed; from Perrin et al. 1983) and winter relative densities (shown as continuous contours of no. schools sighted per $185 \mathrm{~km}$ searched; from Au \& Perryman 1985)
Fig. 2. Stenella coeruleoalba and Delphinus delphis. Striped and common dolphin historical distribution boundaries (from Perrin et al. 1983) and winter relative densities (contours of no. schools sighted per $185 \mathrm{~km}$ searched; from Au \& Perryman 1985) 


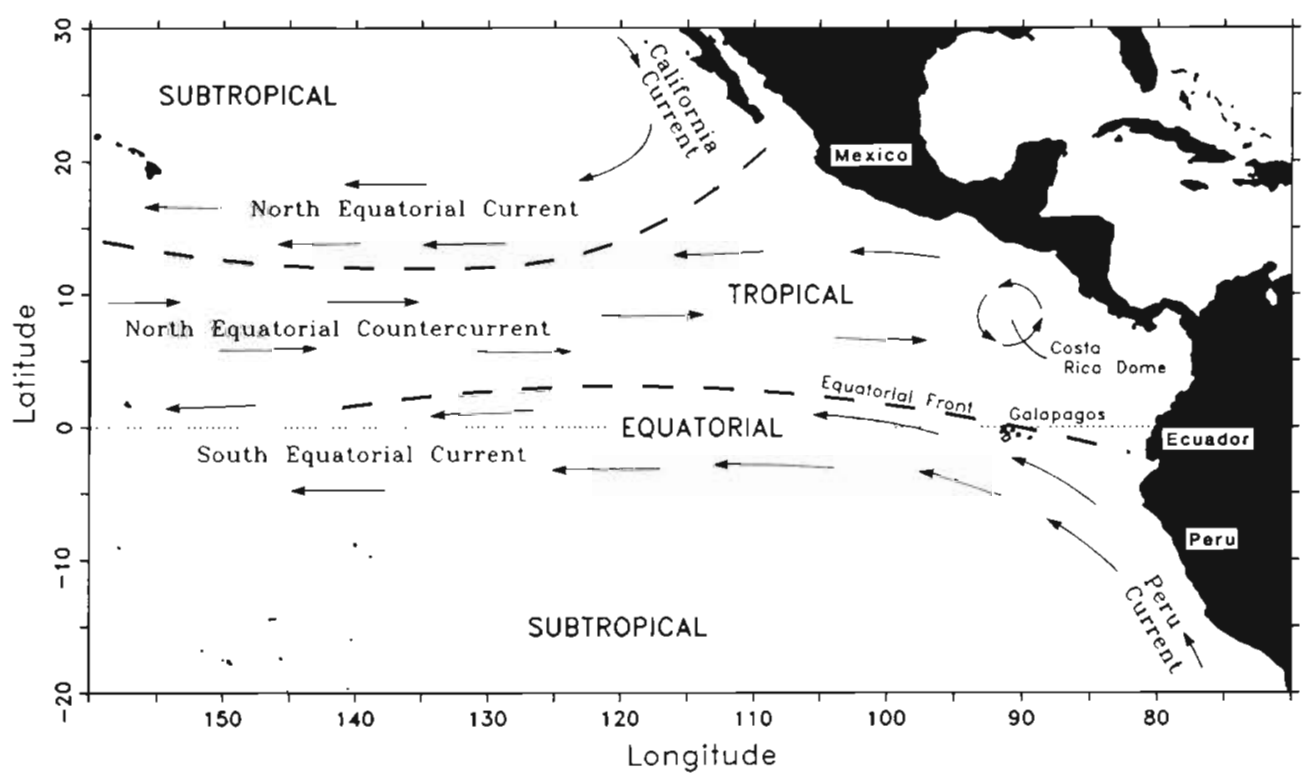

Fig. 3. Schematic representation of the surface water masses and surface circulation of the eastern tropical Pacific, adapted from Wyrtki $(1966,1967)$

clines forming in subtropical and eastern equatorial waters. Biological productivity is enhanced by vertical nutrient flux to the euphotic zone along the zonal divergences (the equatorial upwelling and $10^{\circ} \mathrm{N}$ thermocline ridge; Love 1972), at the Costa Rica Dome (a quasi-permanent cyclonic eddy near $9^{\circ} \mathrm{N}$ and $89^{\circ} \mathrm{W}$; Wyrtki 1964, King 1986), and through zonal advection from coastal upwellings (e.g. the Gulf of Tehuantepec ${ }_{i}$ Owen \& Zeitschel 1970). Secondary and higher level productivity and standing stocks are generally high in areas of high primary productivity (Blackburn et al. 1970). One of McGowan's (1974) Pacific Ocean 'biotic provinces' lies within these boundaries, maintained in part by recirculation of water due to the countercurrent systems. The historical distributions of spotted and spinner dolphins within the ETP (Fig.1) clearly coincide in shape and location with the ETP Biotic Province.

Within this and other large oceanic regions, the abundance of animals from plankton to large nekton is patchy on a variety of spatial and temporal scales (Haury et al. 1978), with major consequences for the ecology of pelagic predators (e.g. Carr 1987). Largescale aggregation of organisms known to be potential prey for pelagic dolphins (cephalopods, meso- and epipelagic fishes; Perrin et al. 1973) can be expected to occur along the equatorial front, and perhaps also around the Costa Rica Dome's upwelling (Owen 1981). Beebe's (1926) classical description of biological activity along a front was recorded at the equatorial front east of the Galapagos. Au \& Perryman (1985) found some though not all spotted and spinner dolphin schools in the immediate area aligned along this front, just within the tropical waters.
Seasonality. Variability in surface circulation is primarily wind driven (Wyrtki 1974), so that processes and features affected by circulation (e.g. convergences and divergences) vary seasonally in response to shifting of the major wind systems. Wyrtki $(1966,1974)$ describes 2 oceanographic seasons in the eastern tropical Pacific. During January to June ('winter') the NE trade winds are strongest and in their most southerly position. At this time the North Equatorial Current (NEC) and opposing North Equatorial Counter Current (NECC) are weakest, as the trades are centered south of the NEC and act against the NECC.

In the second half of the calendar year ('summer') as the Intertropical Convergence Zone (where the NE and $\mathrm{SE}$ trade winds meet) moves northward from its winter minimum latitude near the equator, the NE trades are centered over and more strongly affect the NEC, and with lessened opposition from the wind, the NECC becomes stronger and is well developed from west of the dateline to near the coast of Central America. The NEC-NECC divergence is strongest at this time, so that the thermocline ridge near $10^{\circ} \mathrm{N}$ rises to within $40 \mathrm{~m}$ of the surface. The SE trades, the Peru Current and the SEC strengthen during the summer, producing greater equatorial upwelling and horizontal transport from the Peru Current.

Seasonal biological changes have not been demonstrated unequivocally for most of the ETP (Blackburn 1981, Vinogradov 1981). The cephalopods and fishes that are potential dolphin prey actively avoid standard net tows used to assess their distribution and abundance (e.g. Clarke 1977), obscuring possible seasonal cycles in existing data. 


\section{DATA AND METHODS}

Data sources. Data from 18 research vessel shipmonths from 1982, 1986 and 1987 (Table 1) were combined to examine 'summer' dolphin distributions. The 1986 and 1987 cruises were the first 2 of a 6 yr program to monitor trends in abundance of ETP dolphins. The cruise tracks were designed to cover the historical range of spotted dolphins in the ETP (the most widely distributed of the 4 species affected by the tuna fishery), stratified by previous density indices (Holt et al. 1987). The cruises used here (Fig. 4) surveyed $49102 \mathrm{~km}$ (Table 1) during daylight hours in which there were functional sighting conditions (Beaufort 4 or less). The surveys were conducted at 10 knots $\left(18.5 \mathrm{~km} \mathrm{~h}^{-1}\right)$, with 2 observers simultaneously on watch, each covering one side of the ship using a pair of $25 \times$ binoculars to search an arc from the ship's bow to about $100^{\circ}$ to the beam (Holt \& Sexton 1990). Dolphin sightings were approached for species identification and estimation of numbers within schools. Line transect abundance estimates from the 1986 and 1987 cruises were reported by Holt \& Sexton (1989, 1990).

Mapping distribution patterns. To allow examination of spatial patterns within the region, and for direct comparability with Au \& Perryman's (1985) winter distribution maps, their methods were followed (with exceptions noted below) for computing relative abundance as encounter rates (schools encountered per $185 \mathrm{~km}$ searched - the approximate distance searched in $1 \mathrm{~d}$ ). The use of encounter rates to index relative abundance requires an assumption of no major spatial gradients in school size; this is generally consistent with available data (Holt et al. 1987). Au \& Perryman (1985) computed moving averages of $5^{\circ}$ lat.-long. blocks to smooth their data, then drew contours by hand. I used the commercial graphics package PLOT88 (Young \& Van Woert 1987; algorithms ZGRID, SZMTH and ZCSEG) to smooth data in $2^{\circ}$ lat.-long. blocks twice and then perform Laplacian interpolation of the

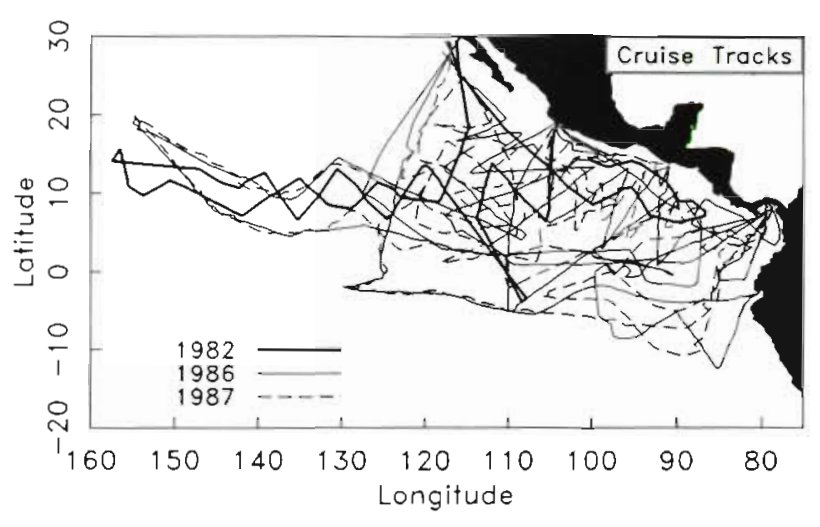

Fig. 4. Cruise tracks of research vessels during summer and fall 1982, 1986 and 1987 (used in this analysis)

smoothed fields. I included only blocks with at least $185 \mathrm{~km}$ search effort.

Also following $\mathrm{Au}$ \& Perryman (1985) data were combined for spotted and spinner dolphins, including in the same category schools where they occurred alone or together. These species are frequently sighted in mixed schools $(73 \%$ of spinner dolphin sightings also included spotted dolphins; Table 1), and not surprisingly their historical (Perrin et al. 1983) and winter (Au \& Perryman 1985) distributions are quite similar. In contrast to Au \& Perryman (1985) data were not combined for common and striped dolphins. While the areas of highest density for these species are similar (Au \& Perryman 1985, this study) they are different in some important ways, described later.

Tests of water mass and thermocline topography as habitat indices. To examine the summer patterns in dolphin sightings in relation to surface water mass characteristics, sigma-t values (a measure of seawater density; see Pickard \& Emery 1982) were computed from surface temperatures and salinities recorded continuously as the vessels traveled. The ships were equipped with ODEC TSG-102 Thermo-salinographs, which sampled temperature with a resolution of $0.1^{\circ} \mathrm{C}$, and salinity with a resolution of 0.01 Practical Salinity Units.

Table 1. Research vessel sighting effort (distance searched) and sightings of dolphin schools recorded during summer and fall 1982, 1986 and 1987 cruises

\begin{tabular}{|c|c|c|c|c|c|c|c|c|}
\hline Date & $\begin{array}{l}\mathrm{km} \text { searched } \\
\text { (n mile) }\end{array}$ & Spotted & Spotted \& Spinner & Spinner & $\begin{array}{l}\text { No. schools of: } \\
\text { Spotted and/or Spinner }\end{array}$ & Striped & Common & Total \\
\hline $\begin{array}{l}1982 \\
\text { Jun-Jul }\end{array}$ & 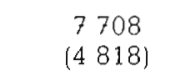 & 22 & 38 & 5 & 65 & 23 & 12 & 100 \\
\hline $\begin{array}{l}1986 \\
\text { Aug-Nov }\end{array}$ & $\begin{array}{c}21845 \\
(13653)\end{array}$ & 86 & 80 & 36 & 202 & 1.57 & 52 & 411 \\
\hline $\begin{array}{l}1987 \\
\text { Aug-Nov }\end{array}$ & $\begin{array}{c}19549 \\
(12218)\end{array}$ & 94 & 75 & 30 & 199 & 184 & 33 & 416 \\
\hline Total & $\begin{array}{cc}49 & 102 \\
(30 & 658)\end{array}$ & 202 & 193 & 71 & 466 & 364 & 97 & 927 \\
\hline
\end{tabular}


For graphic display, temperature and salinity data were averaged within $2^{\circ}$ blocks, smoothed and interpolated, following the methods used to compute and display dolphin encounter rates.

Intermittent problems with the thermo-salinograph on the 1982 cruise resulted in the absence of data for many areas surveyed that year, and a bias in spatial coverage. Consequently, data from 1982 were not included in the following statistical analyses, and the sample size for these analyses was the sum of the 1986 and 1987 observations (827) from Table 1.

To examine relationships with thermocline topography I used depths of the $20^{\circ} \mathrm{C}$ isotherm (Z20, commonly used to indicate location of the thermocline in the tropical Pacific; Hansen \& Herman 1988) taken from XBTs deployed 4 to 6 times daily (every 55 to $110 \mathrm{~km}$ ), and other XBTs deployed in the vicinity as reported to NOAA's National Ocean Survey (SEAS Office, N/OS1, 6001 Executive Blvd., Rockville, MD 20852, USA). For statistical comparisons with dolphin distributions, the $2^{\circ}$ block mean values for sigma-t and $\mathrm{Z} 20$ were assigned to each of 827 sightings according to the $2^{\circ}$ block in which they were recorded.

Univariate (ANOVA) and multivariate analysis of variance (MANOVA) were used to test the continuous distributions of sigma-t and Z20 for significant differences among sighting locations for 3 types of dolphin school: spotted and spinner (all sightings combined). common, and striped dolphins. Success in classifying the sightings to dolphin school type based on these habitat variables was judged by discriminant analysis (e.g. Cooley \& Lohnes 1971), with school types as a priori groups.

As a check on the significance of the univariate and multivariate F-ratios, and the classifications from the discriminant analysis, these were compared to results expected from a random assortment of the sightings, using Monte Carlo methods (Hope 1968, Hair et al. 1987). This verification was done by randomly assigning each case (sighting with associated sigma-t and $\mathrm{Z} 20$ values) to one of the 3 school types, with overall proportions as in the original data (ca 10\% common, $41 \%$ striped and $49 \%$ spotted and spinner). The randomized data set was then tested by ANOVA and MANOVA for significant habitat differences among the pseudo-school types, followed by a classification of cases based on their discriminant function scores. This entire process was repeated 1000 times (Hope 1968) to produce reference sets of random uni- und multivariate F-ratios and classification results. The original F-ratios and classification results were then compared with these reference sets to assess the probability that the originals could have been obtained at random (i.e. Type I statistical error).

It was possible to test for seasonal differences in the sigma-t values of areas where the 3 school types were seen, because Au \& Perryman (1985) gave a table reporting frequencies of sightings by sigma-t intervals. I could not conduct a similar test for Z20 seasonal differences because they did not publish such data for the winter sightings.

All statistical analyses were conducted with the commercial software package SYSTAT (Wilkinson 1988).

\section{RESULTS}

\section{Summer geographic distributions}

Differences between winter distribution patterns from Au \& Perryman (1985) and the summer patterns reported here are apparent for spotted/spinner dolphins and striped dolphins. No seasonal changes are apparent for common dolphins.

In the summer data, spotted and spinner dolphin distribution extended westward along $10^{\circ} \mathrm{N}$ (Fig. 5a), similar to their historical range (Fig. 1). The zonal lobe along $4^{\circ} \mathrm{N}$ between 90 and $120^{\circ} \mathrm{W}$, described by $\mathrm{Au} \&$ Perryman (1985) as prominent in winter (Fig. 1) was very weak during summer. During both winter and summer the area of highest abundance was off southern Mexico, with low abundance between the coast of South America and the Galapagos Islands. The winter lobe centered at $6^{\circ} \mathrm{S}$ was nearly absent in summer. Striped dolphin distribution also extended offshore in the summer data (Fig.5b), similar to the historical boundary (Fig. 2), but in a relatively patchy pattern.

There appears to be little seasonal change in common dolphin distribution. Their abundance centers in summer (Fig. 5c), as in winter (Fig. 2), were relatively coastal, along Baja California and extending offshore to near the Revillagigedos Is. (about $115^{\circ} \mathrm{W}$ and $20^{\circ} \mathrm{N}$ ), along the coast of Ecuador where the Peru Current extends to the northwest, and in a very localized center in the vicinity of the Costa Rica Dome. Common dolphins are occasionally sighted far offshore (Fig. 1), but the effort-corrected data for both the summer and winter show that they occur much less frequently outside of the coastal areas and the equatorial zone east of about $100^{\circ} \mathrm{W}$ (Figs. 2 and $5 \mathrm{c}$ ). The areas where the 3 school types were most abundant (contours of 2 or more schools sighted per $185 \mathrm{~km}$ searched) were spatially separated, with a few exceptions (Fig. 5).

\section{Water mass and thermocline depth as habitat indices}

There was considerable overlap among dolphin school types in the occupied ranges of both surface density and thermocline depth values (Fig. 6), but the 

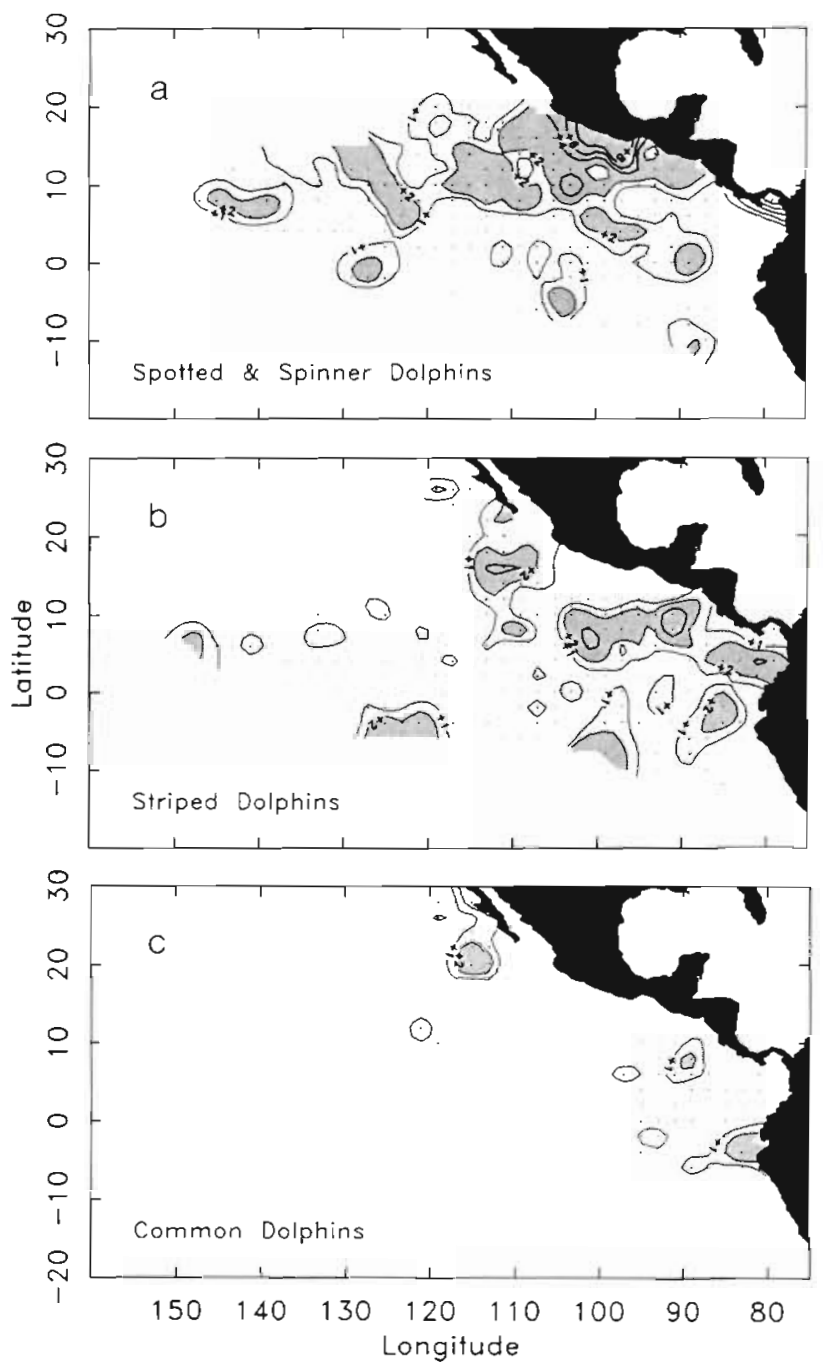

Fig. 5. Summer dolphin distributions in the ETP (contours of encounter rates per $185 \mathrm{~km}$ searched). Dots represent centers of $2^{\circ}$ squares in which there was at least $185 \mathrm{~km}$ search effort. (a) Spotted plus spinner dolphins; (b) striped dolphins; (c) common dolphins

means for both variables were significantly different among the 3 school types, as detailed below.

\section{Water mass characteristics}

In the summer, spotted and spinner dolphins occupied the most tropical water of the species examined here (sigma-t mean $=21.2, \mathrm{SE}=0.071, \mathrm{n}=$ $401, \mathrm{CV}=6.7 \%$ ). Common dolphins occupied less tropical areas on average (mean sigma-t $=22.2, \mathrm{SE}=$ $0.183, n=85, \mathrm{CV}=7.6 \%$ ), but this frequency distribution is bimodal, so a mean or other measure of central tendency is of limited value. Striped dolphins were found in areas that are, on average, intermediate between means for the other species (sigma-t mean =
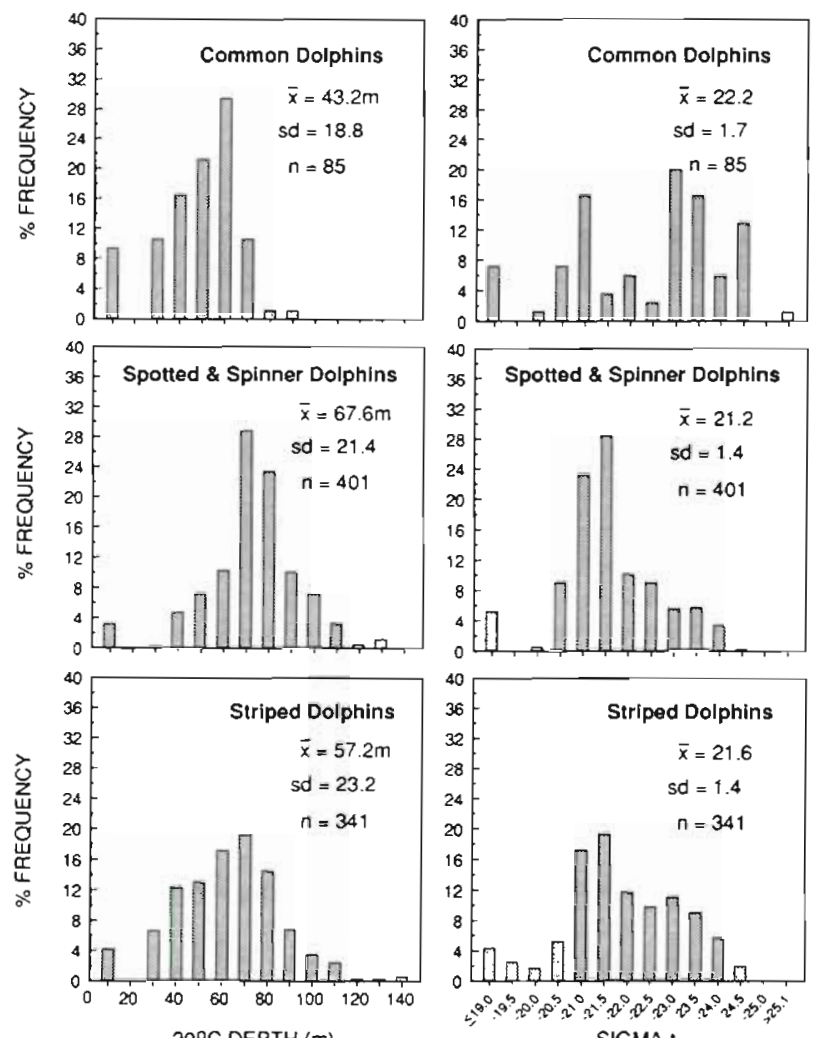

$20^{\circ} \mathrm{C}$ DEPTH (m)

SIGMA-I

Fig. 6. Frequency histograms, transformed to percentages, of surface water density (sigma-t) and $20^{\circ} \mathrm{C}$ isotherm depths (m) (Z20) in areas where dolphins were sighted, by dolphin school type

21.6, $\mathrm{SE}=0.073, \mathrm{n}=341, \mathrm{CV}=6.3 \% \mathrm{l}$. The 3 means are significantly different (Table 2 ), but this result alone is inconclusive because the ANOVA assumptions of normality (Fig. 6) and homogeneity of variances are violated. However, results of the Monte Carlo runs supported the conclusion of a very low Type I error $(p<0.001)$. The largest F-ratio from the 1000 runs was just 6.8 , as compared to the 16.9 observed.

Thermocline characteristics

Spotted and spinner dolphins were sighted in areas with thermoclines relatively deeper than the other 2 species, but intermediate for the entire region ( $Z 20$ mean $=67.72 \mathrm{~m}, \mathrm{SE}=1.066, \mathrm{n}=401, \mathrm{CV}=32 \%$ ). Common dolphins were seen, on average, in areas with shallower thermoclines ( $\mathrm{Z} 20$ mean $=43.16 \mathrm{~m}, \mathrm{SE}=$ 2.037, $\mathrm{n}=85, \mathrm{CV}=44 \%$ ). This includes areas where the $20^{\circ} \mathrm{C}$ isotherm breaks the surface due to upwelling. Striped dolphins were found in waters with thermocline depths intermediate between these, on average $(\mathrm{Z} 20$ mean $=57.20 \mathrm{~m}, \mathrm{SE}=1.256, \mathrm{n}=341, \mathrm{CV}=$ $41 \%$ ). The standard errors of means reported above are 
Table 2. Analyses of variance testing the null hypothesis of no differences among dolphin school types in water mass (sigma-t) and thermocline depth (indexed by depth of $20^{\circ} \mathrm{C}$ isotherm, Z20) of their sighting locations

\begin{tabular}{|c|c|c|c|c|c|c|}
\hline $\begin{array}{l}\text { Univariate analyses } \\
\text { Source }\end{array}$ & SS & $\mathrm{df}$ & MS & $\mathrm{F}$ & $\mathrm{p}$ & $\mathrm{p}_{M C^{\circ}}$ \\
\hline Sigma-t & 68.846 & 2 & 34.423 & 16.9 & $<0.001$ & $<0.001$ \\
\hline Error & 1677.329 & 824 & 2.036 & & & \\
\hline $\mathrm{Z} 20$ & 49507.278 & 2 & 24753.639 & 51.7 & $<0.001$ & $<0.001$ \\
\hline Error & 394919.027 & 824 & 479.271 & & & \\
\hline \multicolumn{7}{|l|}{ Multivariate analyses } \\
\hline Wilke's lambda ${ }^{b}=0.840$ & \multicolumn{4}{|c|}{ Rao's $F^{b}=37.487$} & $\mathrm{p}<0.001$ & $\mathrm{p}_{M C^{\mathrm{d}}}<0.001$ \\
\hline
\end{tabular}

all quite small, a result of sample sizes being relatively large ( 85 to 401 ). These 3 means are significantly different (Table 2). As with the sigma-t univariate test, the Monte Carlo results appear to verify the very low Type I error. The largest F-ratio of the 1000 run reference set was just 9.1 .

\section{Multivariate analyses}

The dolphin school types occupied significantly different habitats, defined by the joint Z20 and sigma-t continuous distributions of their sighting localities. That is, a MANOVA resulted in rejection of the null hypothesis of no differences among school types (Table 2). Classification of individual sightings to dolphin school type from their discriminant function scores resulted in the following success rates: spotted/spinner, $66 \%$; common, $64 \%$; striped, $24 \%$ (Table 3).

Table 3. Classification table from discriminant analysis of dolphin school types by habitat variables (sigma-t and Z20, depth of the $20^{\circ} \mathrm{C}$ isotherm). Successful classifications are represented on the diagonal

\begin{tabular}{|lcccc|}
\hline \multicolumn{5}{c|}{ Predicted group } \\
Actual & Common & $\begin{array}{c}\text { Spotted/ } \\
\text { group }\end{array}$ & Striped & Totals \\
\hline Common & $\mathbf{5 4}$ & 11 & 20 & 85 \\
& $\mathbf{( 6 3 . 5 )}$ & $(13.0)$ & $(23.5)$ & $(100 \%)$ \\
Spotted/ & 45 & $\mathbf{2 6 6}$ & 90 & 401 \\
spinner & $(11.2)$ & $\mathbf{( 6 6 . 4 )}$ & $(22.4)$ & $(100 \%)$ \\
& 125 & 134 & $\mathbf{8 2}$ & 341 \\
Striped & $(36.7)$ & $(39.3)$ & $\mathbf{( 2 4 . 0 )}$ & $(100 \%)$ \\
Totals & 224 & 411 & 192 & 827 \\
\hline
\end{tabular}

In 1000 runs of the Monte Carlo procedure, a significant difference among the 3 randomized groups ( $p \leqslant 0.05$ for the multivariate $F$ ) occurred only twice $(0.2 \%)$. No multivariate $F$ values from the simulations exceeded that observed for the actual data (37.5), verifying the conclusion that the probability of Type I error was less than 0.001 .

Similarly, the school type classifications from the 1000 randomized (Monte Carlo) Discriminant Analyses appear to verify the classifications actually observed, but only for 2 of the 3 school types. For spotted and spinner dolphins, the mean 'hit score' of the reference set was $42.7 \%$. Only 4 of 1000 runs had scores exceeding the $63.5 \%$ actually observed (probability of Type I error $=0.004)$. For common dolphins, the mean hit score of the reference set was just $32.2 \%$. None of the 1000 runs had scores greater than the $66.3 \%$ actually observed $(\mathrm{p}<0.001)$. For striped dolphins, the mean hit score of the reference set was $32.6 \%$. The observed score of $24 \%$ is not significantly different from this mean $(t=0.67, p=0.57$ ), indicating that we could do as well at correctly classifying striped dolphin sightings by random guessing, without considering the habitat data.

\section{Seasonal contrast}

During the summer all 3 dolphin types had significantly different sigma-t distributions as compared with their winter distributions from Au \& Perryman (1985) ( $p<0.001$ for all 3 tests). The summer sigma-t distributions are shifted to lower values reflecting seasonal warming of surface waters.

\section{DISCUSSION}

\section{Seasonal changes in geographic distribution}

Seasonal changes in the locations of high density areas were observed for spotted, spinner and striped dolphins, but not for common dolphins. The most apparent change was the presence of high density areas west of $120^{\circ} \mathrm{W}$ along $10^{\circ} \mathrm{N}$ during the summer; 
this was more prominent for spotted and spinner dolphins, less so for striped. Concomitant with the presence of this summer density center for spotted and spinner dolphins was the absence of the winter high density areas along $4^{\circ} \mathrm{N}$ between 90 and $120^{\circ} \mathrm{W}$, and along $6^{\circ} \mathrm{S}$ between 88 and $110^{\circ} \mathrm{W}$. One hypothesis suggested by these complementary changes is an intraregional, seasonal movement. The distance from the approximate center of the winter area along $4^{\circ} \mathrm{N}$ to the center of the summer area along $10^{\circ} \mathrm{N}$ is over $2500 \mathrm{~km}$, consistent in direction but about twice the maximum distance observed in the limited amount of available mark-recapture data (Perrin et al. 1979, Hedgepeth 1985). A population movement between the western and southern parts of the region is also consistent with patterns of intraspecific morphological variability (Perrin et al. 1985), which indicate more similarity between spotted and spinner dolphins from these western and southern areas than between individuals from either area and those from the high-density center off Mexico.

The observed seasonal changes in dolphin distribstion are at least partially explainable in light of seasonal changes in the atmosphere and ocean. The offshore extension along $10^{\circ} \mathrm{N}$ of spotted, spinner and striped dolphins in the summer clearly coincides with the northward movement of the Intertropical Convergence Zone, the subsequent increase in flow of the NEC and NECC and shoaling of the thermocline ridge at their divergence. Spotted, spinner and striped dolphins appear to aggregate in this area when the thermocline shoals under the tropical surface water, approximating physical conditions occurring in the more nearshore, more densely occupied parts of their ranges east of $125^{\circ} \mathrm{W}$.

The summer decrease in spotted and spinner dolphin abundance at the density center along $6^{\circ} \mathrm{S}$ also coincides with a major seasonal oceanographic change. During the northern summer the Peru Current and SEC are stronger and push farther north in the ETP, and the warm surface layer over the normally subtropical surface water, present in the winter when spotters and spinners are abundant there, recedes to the north. Spotted and spinner abundance was lower during the period of cool, subtropical conditions south of the equator.

The seasonal variation in spotted and spinner distribution occurs in the southern and western parts of the ETP. The triangular, high-density area off Mexico is in the same location, and has the highest density of schools, during both winter and summer. This is the most tropical part of the ETP and has the least seasonally variable oceanography conditions of the region (Wyrtki 1965b, 1974).

Common dolphin distribution does not undergo major seasonal shifts in the ETP. The locations of the year-round density centers best fit Au \& Perryman's (1985) description of 'upwelling modified' habitat, being localized near the Revillagigedos Is., along the coast of Baja California and Ecuador, and near the Costa Rica Dome.

If seasonal variations in biological productivity along the $10^{\circ} \mathrm{N}$ thermocline ridge are small (and perhaps not verified), what accounts for the substantial seasonal variation in dolphin abundance there? It may be related to seasonal change in availability, rather than abundance, of their prey. The shallow thermocline may act as a vertical aggregating mechanism and barrier to rapid escape by the squids and fishes dolphins prey upon (Green 1967) so that when the thermocline reaches some minimum depth range, spotted, spinner and striped dolphins can successfully forage there. During the summer this area is also an important part of the distribution of surface-schooling yellowfin tuna (Calkins 1975), which forage similarly to (and frequently with) these dolphin species.

As noted by $\mathrm{Au} \&$ Perryman (1985) the winter density center along $4^{\circ} \mathrm{N}$ coincides in location with a major zonal convergence at the meeting of the NECC and SEC. This convergence is thought to form the equatorial front (Pak \& Zaneveld 1974), and consequent aggregation of potential dolphin prey (e.g. Sette 1955 , Murphy \& Shomura 1972, Greenblatt 1979). However, the prey aggregation hypothesis is not strongly supported by the seasonal change in dolphin abundance here, as this convergence zone is less abundantly occupied by spotted and spinner dolphins during the summer, when frontal structures are best developed. Perhaps during stronger upwelling periods there is insufficient time for development of an abundant dolphin prey community during the transit of water to the convergence zone (Le Fevre 1986).

\section{Dolphin habitats}

The spatial separation of density centers for spotted and spinner dolphins from centers for common and striped dolphins, reported by Au \& Perryman (1985) for the winter months, appears to be a year-round pattern. While the locations of some density centers varied from winter to summer, there was still separation among species. I also found striped dolphin distribution in the summer to be spatially different from common dolphin distribution, in contrast to the winter condition reported by Au \& Perryman (1985).

The distribution of 2 of the 3 school types (spotted/ spinner; common dolphins) were statistically separable based on thermocline depth and surface water density. This is consistent with the spatial separation of high density centers, and indicates moderate success in 
indexing physical habitats for these ETP dolphins, at least on the spatial and temporal scales of this study.

Striped dolphin distribution was found to be intermediate between the distributions of common and spotted/spinner dolphins, both qualitatively and quantitatively. While the univariate means and multivariate centroids of $\mathrm{Z} 20$ and sigma-t were statistically different from those for the other species, these statistical differences are probably not ecologically meaningful. This is emphasized by the clear lack of success in post-classifying striped dolphin sightings based on Z20 and sigma-t. That is, the spatial separation of striped dolphin density centers from centers for the other dolphin school types (Fig.5) was not reflected robustly in the multivariate statistical analyses of habitat characteristics. This suggests that other processes, not directly related to physical habitat as defined and measured here, act to separate these dolphins from the others.

Other statistical comparisons of ETP cetacean distribution and environmental variables were made by Reilly (1977) and Polacheck (1987). Both studies used sightings from observers on tuna vessels and climatological oceanographic data, summarized in $5^{\circ}$ blocks. Both produced statistically equivocal results, probably resulting from the biased searching of tuna vessels in relation to dolphin distributions (Edwards 1989, Edwards \& Kleiber 1990), the lack of precision inherent in climatologies, and the large spatial units used. However, Polacheck's (1987) results for spotted and spinner dolphins were generally consistent with those of Au \& Perryman (1985) and this study regarding gross spatial patterns, and the existence of some underlying associations between physical environmental variables and dolphin distribution.

\section{Caveats}

Many of the smaller details of the maps may reflect data collection and processing as much as the true shape of the distributions. Pooling data into $2^{\circ}$ lat.long. blocks imposed a minimum level of resolution on the results. Smoothing and interpolation necessary to produce fields appropriate for study of regional patterns is done at the expense of fine-scale detail. If dolphin school types separate on spatial scales smaller than that examined here (which has been the author's personal observation) this separation would not have been detected in the maps or statistical analyses.

Inter-annual variation is another possible source of error here. It is possible that the number of years sampled in both the winter series ( 4 by Au \& Perryman 1985 ) and summer series ( 3 by this study) were not sufficient to fully represent 'typical' seasonal patterns. We will examine patterns of interannual variation in summer dolphin distribution at the close of the 6 yr sampling program in 1992. We are also investigating meso- and smaller scale patterns of sightings and contemporaneously measured environmental properties to determine the scale dependency (e.g. Schneider \& Duffy 1985) of dolphin distributions and physical habitat.

Acknowledgements. R. Holt and S. Sexton graciously provided the sightings and effort data. $V$. Thayer, L. Lierheimer, G. Thomas, P. Fiedler, J. Ellingson, B. McDonald, B. Tershey and L. Magnum collected the oceanographic data. R. Holland provided invaluable assistance with data processing and graphic presentation. D. Au, L. Ballance, D. DeMaster, A. Dizon, P. Fiedler, W. Perrin, R. Pitman and 3 anonymous reviewers made many useful comments on the drafts. I thank these people, plus the dolphin observers, officers and crew of the 'David Starr Jordan' and 'McArthur' for their contributions.

\section{LITERATURE CITED}

Au, D. W. K., Perryman, W. L. (1985). Dolphin habitats in the eastern tropical Pacific. Fish Bull. U.S. 83 (4): 623-643

Beebe, W. (1926). The Arcturus adventure. Putnam \& Sons, New York

Blackburn, M. (1981). Low latitude gyral regions. In: Longhurst, A R. (ed.) Analysis of marine ecosystems. Academic Press, New York p. 3-29

Blackburn, M., Laurs, R. M., Owen, R. S., Zeitschel, B. (1970). Seasonal and areal changes in standing stocks of phytoplankton, zooplankton and micronekton in the eastern tropical Pacific. Mar. Biol. 7 : 14-31

Calkins, T. P. (1975). Geographical distribution of yellowfin and skipjack tuna catches in the eastern Pacific Ocean, and fleet and total catch statistics, 1971-1974. Bull. interAm. trop. Tuna Commn 17: 1-116

Carr, A. (1987). New perspectives on the pelagic stage of sea turtle development. Conserv. Biol. 1 (2): 103-121

Clarke, M. R. (1977). Beaks, nets and numbers. Symp. zool. Soc. Lond. 38: 89-126

Condy, P. R., van Aarde, R. J., Bester, M. N. (1978). The seasonal occurrence and behavior of killer whales, Orcinus orca, at Marion Island. J. Zool., Lond. 184 (4): 449-464

Cooley, W. W., Lohnes, P. R. (1971). Multivariate statistical analysis. John Wiley \& Sons, New York

Edwards, E. F. (1989). Using tuna vessel observer data to detect trends in abundance of dolphin populations: history and research to date (1988). NOAA tech. Memo., NMFSSWFC-122

Edwards, E. F., Kleiber, P. M. (1990). Effects of nonrandomness on estimates of dolphin school abundance derived from tuna vessel observer data. Fish. Bull. U.S. (in press)

Evans, W. E. (1975). Distribution, differentiation of populations, and other aspects of the natural history of Delphinus delphis Linnaeus in the northeastern Pacific. Ph. D. thesis, Univ. of Calif. Los Angeles

Gaskin, D. E. (1982). The ecology of whales and dolphins. Heinemann, London

Green, R. E. (1967). Relationships of the thermocline to success of purse seining for tuna. Trans. Am. Fish. Soc. 96: $126-130$

Greenblatt, P. R. (1979). Associations of tuna with flotsam in the eastern tropical Pacific. Fish. Bull. U.S. 77: 147-155 
Hair, J. F. Jr., Anderson, R. E., Tatham, R. L. (1987). Multivariate data analysis with readings. Macmillan, New York

Hansen, D. V., Herman, A. (1988). A seasonal isotherm depth climatology for the eastern tropical Pacific. NOAA tech. Rep. 434-AOML 33 (Revised)

Haury, L. R., McGowan, J. A., Wiebe, P. H. (1978). Patterns and processes in the time-space scales of plankton distributions. In: Steele, J. H. (ed.) Spatial pattern in plankton communities. Plenum Press, New York, p. 277-327

Hedgepeth, J. B. (1985). Database for dolphin tagging operations in the eastern tropical Pacific, 1969-1978, with discussion of 1978 tagging results. Southwest Fisheries Center Admin. Rept. No. LJ-85-03, p. 1-40

Holt, R. S., Gerrodette, T., Cologne, J. B. (1987). Research vessel survey design for monitoring dolphin abundance in the eastern tropical Pacific. Fish. Bull. U.S. 85 (3): 435-446

Holt, R. S., Sexton, S. N. (1989). Monitoring trends in dolphin abundance in the eastern tropical Pacific using research vessels over a long sampling period: analysis of 1987 data. Rep. int. Whal. Commn 39: 347-351

Holt, R. S., Sexton, S. N. (1990). Monitoring trends in dolphin abundance in the eastern tropical Pacific using research vessels over a long sampling period: analyses of 1986 data, the first year. Fish. Bull. U.S. 88 (1): 105-111

Hope, A. C. A. (1968). A simplified Monte Carlo significance test procedure. J. R. statist. Soc. Ser. B 30 (3): 582-598

Jonsgard. A., Lyshoel, P. B. (1970). A contribution to the knowledge of the biology of the killer whale. Norw. J. Zool. 18: 41-48

King, F. D. (1986). The dependence of primary production in the mixed layer of the eastern tropical Pacific on the vertical transport of nitrate. Deep-Sea Res. 33 (6): 733-754

Le Fevre, J. (1986). Aspects of the biology of frontal systems. In: Blaxter, J. H. S., Southward, A. J. (eds.) Advances in marine biology, Vol. 23. Academic Press, New York

Leatherwood, J. S., Walker, W. A. (1979). The northern right whale dolphin Lissodelphis borealis Peale in the eastern north Pacific. In: Winn, H. E., Olla, B. L. (eds.) Behavior of marine animals, Vol. 3: Cetaceans. Plenum Press, New York, p. 85-141

Love, C. M. (ed.) (1972). Biological and nutrient chemistry data from principal participating ships, second survey cruise, August-September 1967. EASTROPAC Atlas Vol. 6. Natl. Mar. Fish. Serv., Circ. 330, p. 1-80

McGowan, J. A. (1974). The nature of oceanic ecosystems. In Miller, C. B. (ed.) The biology of the oceanic Pacific. Oregon St. Univ. Press, Corvallis, p. 9-28

Mercer, M. C. (1975). Modified Leslie-DeLury population models of the long-finned pilot whale (Globicephala melaena) and annual production of the short-finned squid (Illex illecebrosus) based upon their interaction at Newfoundland. J. Fish. Res. Bd Can. 32: 1145-1154

Miyazaki, N., Kasuya, T., Nishiwaki, M. (1974). Distribution and migration of two species of Stenella in the Pacific coast of Japan. Sci. Rep. Whales Res. Inst., Japan 26: 227-243

Murphy, G. I., Shomura, R. S. (1972). Pre-exploitation abundance of tunas in the equatorial central Pacific. Fish. Bull. U.S. 70 (3) 785-905

Owen, R. W (1981). Fronts and eddies in the sea: mechanisms, interactions and biological effects. In: Longhurst, A. R. (ed.) Analysis of marine ecosystems. Academic Press New York, p. 197-227

Owen, R. W., Zeitschel, B. (1970). Phytoplankton production seasonal changes in the oceanic eastern tropical Pacific Mar. Biol. ? (1): 32-36

Pak, H., Zaneveld, J, R. V. (1974). Equatorial front in the eastern Pacific Ocean. J. phys. Oceanogr. 4: 570-580
Perrin, W. F. (1969). Using porpoise to catch tuna. Wld Fish. 18 (6) : $42-45$

Perrin, W. F. (1975). Distribution and differentiation of populations of dolphins of the genus Stenella in the eastern tropical Pacific. J. Fish. Res. Bd Can. 32: 1059-1067

Perrin, W. F. (1988). Dolphins, porpoises and whales - an action plan for the conservation of biological diversity 1988-1992. IUCN, Gland, Switzerland

Perrin, W. F., Warner, R. R., Fiscus, C. H., Holts, D. B. (1973) Stomach contents of porpoise, Stenella spp., and yellowfin tuna, Thunnus albacares, in mixed-species aggregations. Fish. Bull. U.S. 71 (4) : 1077-1092

Perrin, W. F., Evans, W. E., Holts, D. B. (1979). Movements of pelagic dolphins (Stenella spp.) in the eastern tropical Pacific as indicated by the results of tagging operations, 1969-76. NOAA techn. Rep. NMFS SSRF-737, p. 1-14

Perrin W. F., Scott, M. D., Walker, G. J., Ralston, F. M., Au, D. W. K. (1983). Distribution of four dolphins (Stenella spp. and Delphinus delphis) in the eastern tropical Pacific, with an annotated catalog of data sources. NOAA techn. Memo NOAA-TM-NMFS-SWFC-38, p. 1-65

Perrin, W. F., Scott, M. D., Walker, G. J., Cass, V L. (1985). Review of geographical stocks of tropical dolphins (Stenella spp. and Delphinus delphis) in the eastern Pacific. NOAA tech. Rep. NMFS 28, p. 1-28

Pickard, G. L. Emery, W. J. (1982). Descriptive physical oceanography. 4th (SI) enlarged edition. Pergamon Press, Oxford

Polacheck, T. (1987). Relative abundance, distribution and interspecific relationship of cetacean schools in the eastern tropical Pacific. Mar. Mammal Sci. 3 (1): $54-77$

Reilly, S. B. (1977). The distribution of pilot whales, Globicephala macrorhynchus Gray, 1896, in the eastern tropical Pacific. M.S. thesis, Calif. Polytech. St. Univ., San Luis Obispo, California

Schneider, D. C., Duffy, D. C. (1985). Scale-dependent variability in seabird abundance. Mar. Ecol. Prog. Ser. 25: 211-218

Selzer, L. A., Payne, P. M. (1988). The distribution of whitesided (Lagenorhynchus acutus) and common dolphins (Delphinus delphis) vs. environmental features of the continental shelf of the northeastern United States. Mar. Mammal Sci 4 (2): 141-153

Sette, O. E. (1955). Consideration of mid-ocean fish production as related to oceanic circulatory systems. J. mar. Res. 14 (4) : $398-414$

Smith, T (1983). Changes in size of three dolphin (Stenella spp.) populations in the eastern tropical Pacific. Fish. Bull U.S. $81(1): 1-13$

Tomilin, A. G. (1967). Mammals of the USSR and adjacent countries. Vol. IX, Cetacea. Translation by Israel Program for Scientific Translation. Heptner, V G. (ed.)

Tsuchiya, M. (1970). Equatorial circulation of the south Pacific. In: Wooster, E. (ed.) Scientific exploration of the South Pacific. Natl. Acad. Sci., Washington, D.C., p. 69-74

Tsuchiya, M. (1974). Variation of the surface geostrophic flow in the eastern intertropical Pacific Ocean. Fish. Bull. U.S. 72 (4): $1075-1086$

Tsuchiya, M. (1982). On the Pacific upper-water circulation. J. mar. Res. (Suppl.) 40: 777-799

Viale, D. (1985). Cetaceans in the northwestern Mediterranean: their place in the ecosystem. Oceanogr. mar. Biol. A. Rev. 23: 491-571

Vinogradov, M. E. (1981). Ecosystems of equatorial upwellings. In: Longhurst, A. R. (ed.) Analysis of marine ecosystems. Academic Press, New York, p. 69-93

Wilkinson, L. (1988). SYSTAT the system for statistics. SYSTAT Inc., Evanston, Illinois 
Wooster, W. S., Cromwell, T (1958). An oceanographic description of the eastern tropical Pacific. Bull. Scripps Instn Oceanogr. $7:$ 169-282

Wyrtki, K. (1964). Upwelling in the Costa Rica Dome. Fish. Bull U.S. 63 : $355-372$

Wyrtki, K. (1965a). Surface currents in the eastern tropical Pacific Ocean. Bull. inter-Am. trop. Tuna Commn 9: 269-304

Wyrtki, K. (1965b). The annual and semiannual variation of the sea surface temperature in the North Pacific Ocean. Limnol. Oceanogr. 10 (3): 307-313

This article was submitted to the editor
Wyrtki, K. (1966). Oceanography of the eastern equatorial Pacific Ocean. Oceanogr. mar. Biol. A. Rev. 4: 33-68

Wyrtki, K. (1967). Circulation and water masses in the eastern equatorial Pacific Ocean. Int. J. Oceanol. Limnol. 1: $117-147$

Wyrtki, K. (1974). Sea level and the seasonal fluctuations of the equatorial currents in the western Pacific Ocean. J. Phys. Oceanogr. 4: 91-103

Young, T L., Van Woert, M. L. (1987). PLOT88 software Library. Plotworks, Inc., La Jolla, California

Manuscript first received: December 6, 1989

Revised version accepted: June 12, 1990 